\title{
Factors associated with continuing emergence of $\beta$-thalassemia major despite prenatal testing: a cross-sectional survey
}

This article was published in the following Dove Press journal:

International Journal of Women's Health

25 September 2017

Number of times this article has been viewed

\author{
Haleama Al Sabbah' \\ Sarah Khan' \\ Abdallah Hamadna ${ }^{2}$ \\ Lamia Abu Ghazaleh ${ }^{2}$ \\ Anwar Dudin² \\ Bashar Adnan Karmi ${ }^{3}$ \\ 'College of Natural and Health \\ Sciences, Zayed University, Dubai, \\ UAE; ${ }^{2}$ Faculty of Medicine, An-Najah \\ National University, Nablus, Palestine; \\ ${ }^{3}$ Thalassemia Patients' Friends \\ Society, Ramallah, Palestine
}

Purpose: Health care initiatives focusing on prenatal testing and premarital genetic screening aiming to reduce the incidence of $\beta$-thalassemia have emerged during the last decade. In Palestine, $4 \%$ of the population are known thalassemia carriers with new cases continuing to appear despite the availability of prenatal testing. This study aims to identify factors that influence the decision to retain or abort fetuses affected by $\beta$-thalassemia in Palestine.

Methods: Convenience sampling was used to select 32 women (72 fetuses) who were at risk of having a baby with $\beta$-thalassemia. A questionnaire on prenatal testing, test results, pregnancy outcomes, and factors influencing the decision to terminate the pregnancy were used for this cross-sectional study. The data were analyzed using SPSS version 17.

Results: Among the fetuses screened, 36 (50\%) were thalassemia carriers and 20 (28\%) had $\beta$-thalassemia; 17 (85\%) affected fetuses were aborted. Religious beliefs were the most cited reason for opposing abortion while prior experience with $\beta$-thalassemia patients and awareness programs promoted abortions. Mothers who opted to retain an affected fetus had modest educational attainment. Higher educational level was significantly associated with the decision to abort an affected fetus $(p<0.05)$.

Conclusion: A religious consensus is needed on the abortion of fetuses affected by $\beta$-thalassemia. Improving female education and increasing awareness on thalassemia could help reduce the incidence of $\beta$-thalassemia in Palestine and around the world.

Keywords: abortion, Islam, fetus, awareness

\section{Introduction}

The thalassemias are a heterogeneous group of genetic disorders characterized by impaired hemoglobin production. Hemoglobin is made up of 2 alpha and 2 beta globin chains; mutations in either the alpha or beta globin genes result in reduced or compromised production of the globin chains of hemoglobin. ${ }^{1}$ Most thalassemias are inherited in a Mendelian recessive fashion, and the severity of the disease varies widely; heterozygotes are usually asymptomatic while homozygotes or compound heterozygotes are more severely afflicted. ${ }^{2}$ Defects in $1 \beta$ allele manifest as $\beta$-thalassemia trait, which is a mild variation of the disease. Where both $\beta$ globin alleles are affected, the resulting condition, thalassemia major, is a severe, life-threatening disease requiring regular transfusions and medical support to aid normal growth and development of the individual. ${ }^{1}$

Hemoglobinopathies represent the most common single gene disorder in the world. ${ }^{3}$ Worldwide, $5 \%$ of the population is suffering from a variant of thalassemia; however, many are asymptomatic, silent carriers. Thalassemia is widely distributed,

\footnotetext{
Correspondence: Sarah Khan

College of Natural and Health Sciences,

Zayed University, PO BOX 19282 ,

Dubai, UAE

Tel +97I 507641992

Fax +971 44021018

Email sarah.khan@zu.ac.ae
}

International Journal of Women's Health 2017:9 673-679 (c) (1) (5) 2017 Al Sabbah et al. This work is published and licensed by Dove Medical Press Limited. The full terms of this license are available at https://www.dovepress.com/terms.php cC. hereby accept the Terms. Non-commercial uses of the work are permitted without any further permission from Dove Medical Press Limited, provided the work is properly attributed. For permission for commercial use of this work, please see paragraphs 4.2 and 5 of our Terms (https://www.dovepress.com/terms.php). 
with the highest prevalence in malaria-endemic tropical and subtropical regions, affecting almost 4.4 per 10,000 live births globally. ${ }^{4}$

Since the late 1960 s, regular transfusion regimens have been promoted for thalassemia major patients to maintain close to normal hemoglobin levels. The use of long-term iron chelation with desferrioxamine prevents iron overload but this treatment is expensive and requires parenteral administration. ${ }^{5}$

Bone marrow transplantation is the only possible cure for thalassemia, if a human leukocyte antigen (HLA)-matched donor is available. ${ }^{6}$ Since thalassemia is predominant in the lower socioeconomic realms of the world, the cost of treating thalassemia is prohibitive to the clear majority of those afflicted even if a donor is available. The annual cost of treating 15,000 thalassemia patients in Iran is estimated to be $\$ 200$ million. $^{7}$ Preimplantation diagnosis by the polymerase chain reaction is considered a viable option to limit the number of new cases of thalassemia. ${ }^{8}$

\section{Thalassemia in Palestine}

A survey carried out in 1996 by the World Health Organization in collaboration with The Thalassemia Patients' Friends Society (TPFS) revealed a $4 \%$ prevalence of thalassemia carriers in Palestine - 1,500,000 carriers. ${ }^{9}$ The relatively high prevalence of thalassemia gene carriers could mean a higher number of thalassemia patients in the future. The Ministry of Health $(\mathrm{MOH})$ of Palestine registered 816 thalassemia patients in $2009 ; 76 \%$ of these patients were born out of consanguineous marriages. ${ }^{9}$ In the Gaza strip, $0.02 \%$ of the population are known to have $\beta$-thalassemia, with IVS-I-110 being the most frequent mutation in the Gaza strip. ${ }^{10}$ The average life expectancy of a thalassemia patient in Palestine is merely 15 years with many thalassemia patients suffering from iron overload - iron levels exceeding 1,000 mg/dL. ${ }^{9}$ The use of unscreened blood in Palestine increases the risk of blood-borne infections in these patients. Inability to maintain normal healthy relationships, fear of the outcome of the disease, and prohibitive costs contribute to further psychological and social stress in patients. National Medical Services are unable to meet the cost of almost $\$ 15,000$ per thalassemia patient per year. ${ }^{9}$ Health care initiatives focusing on prenatal testing and premarital genetic screening aiming to reduce the incidence of thalassemia have emerged during the last decade. ${ }^{11}$

A premarital screening program for $\beta$-thalassemia carriers aimed to reduce the incidence of thalassemia by discouraging marriage between known thalassemia carriers. For carriers married before the year 2000, prenatal diagnoses through chorionic villus sampling (CVS) and amniocentesis were introduced to supplement the screening program. ${ }^{11}$ Amniocentesis for prenatal diagnosis of chromosomal anomalies is performed at 16-20 weeks of gestation. ${ }^{12}$ On the other hand, CVS is performed earlier, typically between the 10th and 12th weeks of gestation, allowing for earlier prenatal diagnosis. ${ }^{13}$

According to the TPFS, there has been a drastic reduction in the incidence of thalassemia during the years 2000-2007 following the establishment of the screening program (Figure 1); yet new cases continue to emerge. ${ }^{9}$

A study conducted in 2005 in the West bank and Gaza concluded that all families with fetuses testing positive for $\beta$-thalassemia decided to abort their fetus. ${ }^{14}$ Nonetheless, there are no published studies that explain the persistence of appearance of new cases in the Palestinian territories despite prenatal testing. There is limited awareness on prenatal diagnosis in Palestine, and there are no laws to guide parents toward making decisions regarding an affected fetus. ${ }^{15}$

\section{Prenatal diagnosis of $\beta$-thalassemia}

Prenatal diagnosis of $\beta$-thalassemia is rapidly gaining importance in reducing the incidence of $\beta$-thalassemia. Research has confirmed the significance of offering prenatal diagnosis to women/couples at risk of having a fetus with clinically significant thalassemia or other hemoglobinopathies. ${ }^{16}$ Since its inception in the 1980s, CVS has gained popularity as a means of rapid prenatal diagnosis in early pregnancy, hence rendering it is less emotionally and physically taxing than second-trimester procedures like amniocentesis. ${ }^{17}$ First-trimester diagnosis of $\beta$-thalassemia allows more options for the affected couples, particularly in countries where abortions are opposed due to religious and cultural

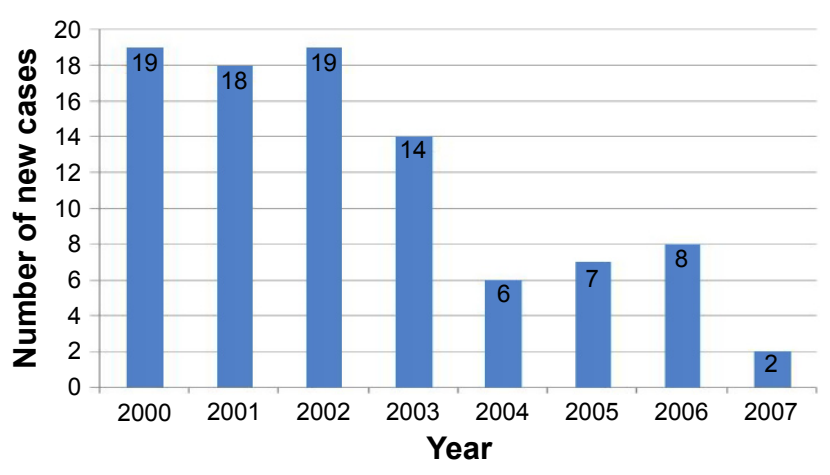

Figure I Number of new cases from year 2000 to 2007 in Palestine. Note: Data from Karmi. 9 
sanctions. Availability of fetal diagnosis gives carrier couples the opportunity to consider procreating, with the possibility of giving birth to a healthy child. ${ }^{14}$

In a study in India, where $29 \%$ of the fetuses included in the study were found to have $\beta$-thalassemia, parents opted for termination of the pregnancy regardless of the gestational age. This denoted the importance of prenatal diagnosis of affected children in developing countries. ${ }^{16}$

\section{Thalassemia and Islam}

Many Islamic scholars have ruled that it is permissible to abort a fetus with serious medical conditions before the "occurrence of soul-breathing" ("ensoulment") at 120 days of gestation. This is based on the Prophetic statement:

The creation of a person takes place in the mother's belly for forty days in the form of a seed, then he is a tiny clinging thing for a like period, then there is sent to him the angel who blows the breath of life into him. ${ }^{18}$

In September 1984, the High Council for Islamic Legal Opinions in Kuwait, and in 1990 the Islamic Jurisprudence Council in Saudi Arabia declared that abortions before 120 days of gestation were permissible only if it was certain that the fetus would be born with an incurable disease or deformity. ${ }^{19}$ Also, in Pakistan Islamic scholars permit termination of pregnancy within 120 days of pregnancy if medical conditions compel it. Nevertheless, in a study in Pakistan, 6 out of 53 fetuses were diagnosed with thalassemia, yet the option to abort was declined on religious grounds. ${ }^{20}$ Recent acceptance of legal abortion in Iran in accordance with Islamic rules has had a major influence on people's attitude toward prenatal diagnosis and the abortion of affected fetuses. ${ }^{13}$

In Palestine, as in many other Islamic countries, abortion is legal only if the pregnancy is a threat to the mother's life or if the fetus shows anomalies incompatible with life following delivery. $\beta$-thalassemia major is not considered an indication for legal abortion in Palestine; therefore, the case is referred to the religious judge (Mufti) to take a religiously sanctioned decision. ${ }^{15}$

Islamic scholars opinions are riddled with controversy surrounding rulings related to thalassemia. ${ }^{21}$ The main dispute revolves around the time of "soul emergence". Some scholars believe that the soul emerges at 40 days and they thus prohibit abortion beyond 40 days of gestation, while others conclude that the soul does not emerge before 120 days of gestation making abortion religiously acceptable before that time; this makes early diagnosis of thalassemia crucial. ${ }^{21}$
A study on $\beta$-thalassemia major patients of Pakistani origin in the UK revealed that Pakistani women's attitudes toward prenatal diagnosis and termination of pregnancy were influenced by a multitude of factors and religion alone should not be taken as a reflection of their attitudes regarding abortion. ${ }^{18}$

This study aims to identify the influencing factors that explain why some parents in Palestine choose to give birth to a fetus affected by $\beta$-thalassemia despite the financial and psychological implications associated with the disease.

\section{Material and methods Study design and settings}

A cross-sectional analytical study was conducted in 5 districts of the Palestinian Authority, namely, Nablus, Tulkarm, Jenin, Ramallah, and Qalqilya.

\section{Study population}

This study included 32 mothers who had undergone prenatal testing. The mothers were registered at the TPFS and the $\mathrm{MOH}$. A convenience sample was obtained from the archives of TPFS during a 3-month period, ranging from January to March of the year 2011. The sample excluded women from regions of Hebron and Bethlehem since TPFS did not have a record of mothers who underwent the test in these districts. From 2002 onwards, 53 patients were registered at TPFS, of whom 32 mothers underwent prenatal diagnosis tests between 2000 and 2011. Most of these mothers already had a child affected with $\beta$-thalassemia major and thus were advised prenatal testing for subsequent pregnancies. The sample was comprised of carrier mothers who had married known $\beta$-thalassemia carrier men. The sample also included mothers who had the prenatal diagnosis test for diagnostic purposes on referral from TPFS and $\mathrm{MOH}$ in Al-Maqased Hospital between the years of 2000 and 2011. Mothers who had prenatal diagnostic tests before 2000 or did not reside in Palestine were excluded from the study.

The target samples were contacted via phone using the TPFS records and recruited after obtaining informed, voluntary consent to participate in the study.

\section{Data collection instrument}

Data were collected through questionnaires filled out by the study researchers. The questionnaire included a brief introduction about the study and its objectives and was administered in Arabic. The questionnaire comprised a total of 20 questions and was divided into 4 sections. 
Section 1: Consisted of 8 questions on social and demographic characteristics.

Section 2: Consisted of 3 questions including the parents' family history, the current family history of thalassemia, and the financial burden it imposes on the family.

Section 3: Included 3 questions on the prenatal test - the year it was done and the gestational age at the time of the test. The gestational age was stratified based on the different religious views, permitting abortion before a specific gestational age. Test results were explored under the categories of normal, carrier, and affected fetuses.

Section 4: Included 6 questions. The main question was about the outcome of pregnancy after receiving the test results. Where abortion was performed, the gestational age at the time of abortion was asked. The family's religious and personal perspectives on abortion were also explored.

\section{Ethics and informed consent}

A written approval to conduct the study was obtained from the An-Najah National University Institutional Review Board on February 22, 2012. Another letter of approval to conduct this study was obtained from the MOH to get access to the thalassemia patients' records. Informed consent was obtained from all participants and they were assured that confidentiality of those involved in the study would be maintained. Permission was taken to publish the data gathered in the research.

All procedures performed in our study involving human participants were in accordance with the ethical standards of the institutional research committee and with the 1964 Helsinki declaration and its later amendments or comparable ethical standards.

\section{Data collection}

A total of 32 meetings were conducted with mothers from the targeted areas. All meetings were conducted with the cooperation of the TPFS centers, in an environment that offered privacy and comfort. In Nablus, a contact number was left at the TPFS center in Al Watani Hospital, and the researchers were contacted to conduct meetings when a mother brought in her child for a blood transfusion. In Tulkarm, Jenin, Qalqilya, Ramallah, and Tubas centers, the TPFS team communicated with the mothers via phone to make arrangements for them to come for a meeting.

\section{Data analysis}

All data were entered, tabulated, and analyzed using version 17 of SPSS software. The principal investigators handled all data themselves to maintain confidentiality. Data were presented as frequencies and cross tabulations. Chi-square analysis was used to relate sociodemographic characteristics and a $p$-value of $<0.05$ was considered significant.

\section{Results \\ Sociodemographic characteristics}

A total of 32 mothers, aged between 22 and 44 years old, were included in this study. Their mean age was 33.56 years and the standard deviation was 4.032 years. According to the patient's records in the TPFS files, 14 out of 32 (43.8\%) mothers were from Nablus, 9 (28.1\%) from Tulkarm, 4 (12.5\%) from Ramallah, 4 (12.5\%) from Jenin, and 1 (3.1\%) from Qalqilya (Figure 2).

The monthly income of the families included in the study ranged from 1,500 to 4,000 New Israeli Shekel (NIS), with a mean of 2,334.38 NIS and standard deviation of 588.25 NIS. According to the Palestinian Central Bureau of Statistics, 2,236 NIS was considered the poverty line for the year 2011.22 Twenty-five families (78.1\%) were below the poverty line while only 7 families $(21.9 \%)$ were above the poverty line (Table 1).

Overall, 17 (53.1\%) mothers had entered high school, $9(28.1 \%)$ had completed elementary school, and 6 (18.8\%) had a Bachelor degree (Table 1).

\section{Health status and perceived financial burden}

Of the participating mothers, 31 had at least one child with thalassemia in the family. Twenty-five $(80.6 \%)$ of the 31 mothers reported that their children were in good health, $4(12.9 \%)$ said their children had recurrent illnesses, and $2(6.5 \%)$ felt their children were in poor health (Table 2$)$. In total, $11(35.5 \%)$ out of these families considered their financial burden to be minimal and mainly due to transportation costs. Another 11 (35.5\%) considered their burden to be moderate and $7(22.5 \%)$ felt the financial burden was high. Only $2(6.5 \%)$ out of 31 felt no financial burden at all. Financial burden was based on the mothers' perceptions.

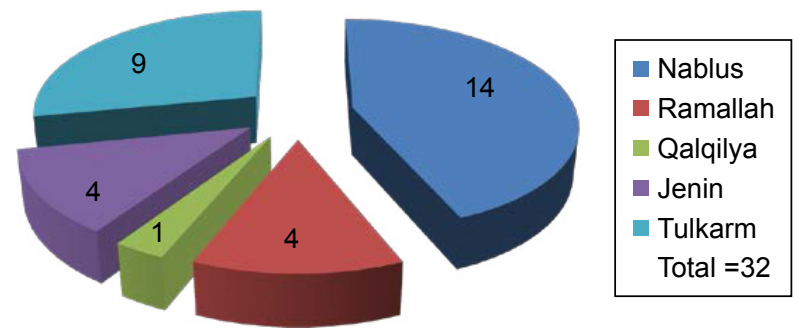

Figure 2 Number of participants from each district in Palestine. 
Table I Sociodemographic characteristics of the study sample

\begin{tabular}{lll}
\hline Variable & $\mathbf{n = 3 2}$ & $\%$ \\
\hline Economic status of family & & \\
- Below poverty line (<2,236 NIS/month) & 25 & 78.1 \\
- Above poverty line (>2,236 NIS/month) & 7 & 21.9 \\
Mother's education & & \\
- Elementary school & 9 & 28.1 \\
- High school & 17 & 53.1 \\
- Diploma & 0 & 0 \\
- Bachelor degree & 6 & 18.8 \\
Fathers education & & \\
- Elementary school & 9 & 28.1 \\
- High school & 15 & 46.9 \\
- Diploma & 1 & 3.1 \\
- Bachelor degree & 7 & 21.9 \\
\hline
\end{tabular}

\section{Prenatal test}

In total, 72 prenatal tests were carried out for the 32 participating mothers. The reason to undergo testing was preexisting thalassemia patients in the family in 60 out of 72 cases. The other 12 tests were done on referrals from obstetricians. The cost of the tests was partially covered by the $\mathrm{MOH}$ for 55 tests out of the $72(76.6 \%)$, while for the remaining $17(23.6 \%)$ tests, expenses were borne by the family.

The gestational age of fetuses at the time of testing was under 120 days in 44 (61\%) cases and between 120-140 days in the other $28(39 \%)$ fetuses. Among the 72 fetuses tested by DNA analysis, $16(22.2 \%)$ were found to be normal, $36(50 \%)$ were thalassemia carriers, and $20(27.8 \%)$ suffered from $\beta$-thalassemia (Figure 3).

Out of the 20 affected fetuses, 17 (70.5\%) were aborted. The decision to abort in 12 cases was due to an unwillingness to have a child with $\beta$-thalassemia after having first-hand experience with thalassemia patients. These parents were familiar with the challenges associated with thalassemia. The remaining 5 (29.5\%) fetuses were aborted based on informed decisions following thalassemia awareness programs organized by TPFS.

Table 2 Health status of affected child and perceived financial burden

\begin{tabular}{|c|c|c|}
\hline Variable & $n=3 \mathbf{I}$ & $\%$ \\
\hline \multicolumn{3}{|c|}{ Current health condition of affected child in the family } \\
\hline - Good health & 25 & 80.6 \\
\hline - Recurrent illness & 4 & 12.9 \\
\hline - Poor health & 2 & 6.5 \\
\hline \multicolumn{3}{|c|}{ Financial burden of caring for a thalassemia patient } \\
\hline - No burden & 2 & 6.5 \\
\hline - Mild burden eg, transportation costs & II & 35.5 \\
\hline - Moderate burden & II & 35.5 \\
\hline - High burden & 7 & 22.5 \\
\hline
\end{tabular}

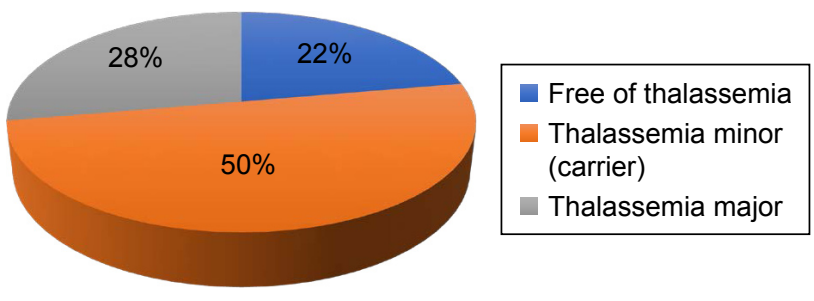

Figure 3 Results of prenatal testing.

Most abortions, 11 (64.7\%) out of 17 were carried out at gestational age of $<120$ days. The remaining 6 (35.3\%) fetuses were aborted between 120 and 140 days of gestation. Interestingly, parents who decided against abortion despite carrying affected fetuses, decided to do so even though the gestational age was $<120$ days. This finding repudiates the relationship between gestational age at time of diagnosis and the decision to abort the fetus.

While $85 \%$ of the affected fetuses were aborted, three families proceeded with the pregnancy despite the test result. Of these, two families cited religious beliefs as their reason for refusing to abort while one family felt the desire to have a baby surpassed the challenges that would be faced in raising a child with thalassemia.

There was no apparent influence of the district from where the people came and their decision regarding the outcome of pregnancy. All families with an affected fetus belonged to a low socioeconomic status ( $<2,236 \mathrm{NIS} /$ month).

There was no impact of the mother's employment status on the outcome of pregnancy. However, the mother's educational level had a significant influence on her decision to keep or abort the fetus $(p<0.05)$. All 3 mothers who decided to keep their baby had considerably modest formal educational. In contrast, all mothers who decided in favor of aborting an affected fetus were more highly educated. Those who refused abortion included 7 (58.4\%) mothers with high school education and only $5(41.6 \%)$ out of 12 with an undergraduate degree.

There was no obvious influence of the fathers' occupation or educational level on the decision to keep or abort the baby.

\section{Relationship between the medical condition of the affected thalassemia family member and the outcome of pregnancy}

All the 3 families who continued with the pregnancy of an affected fetus already had a child with thalassemia in the family. Among the 12 families who aborted the fetus, 11 families already had a case of thalassemia in the family. 
Thus, there was no significant relationship between the current health status of a thalassemic child in the family and the outcome of pregnancy.

There was no relationship between the financial burden of having a child with thalassemia in the family and the decision to keep or abort an affected fetus.

\section{Religious opinion of mothers}

On inquiring about the families' religious point of view regarding abortion, $10(31.3 \%)$ out of 32 mothers believed abortion was forbidden regardless of the gestational age, $20(62.5 \%)$ mothers thought abortion was permissible under such conditions, and $2(6.2 \%)$ mothers remained neutral to religious views.

Among 12 mothers who had undergone at least 1 abortion, $4(33.3 \%)$ believed abortions were forbidden in Islam. A total of 7 (58.3\%) mothers thought abortions were permissible in medically sanctioned conditions and $1(8.4 \%)$ mother remained noncommittal.

\section{Discussion}

A religious directive regarding abortion of fetuses affected by $\beta$-thalassemia major remains elusive. The conflict of religious opinions on the gestational age before which abortion is acceptable indicates the need for as early a diagnosis as possible. ${ }^{18}$ A previous study done in Palestine concluded that prenatal diagnosis should be performed before the 17 th gestational week (119 days), as this would increase the possibility of religiously accepted termination of pregnancy of an affected fetus. ${ }^{14}$ However, in this study, we did not find a relationship between the time of performing the test, the gestational age, and the outcome of pregnancy. Out of 17 fetuses, 11 (64.7\%) were aborted before 120 days' of gestational age while the other 6 fetuses $(35.3 \%)$ were aborted at 120-140 days. Contrary to indications given by other studies, all those who decided to continue their pregnancies despite having an affected fetus did so even though the fetus was under 120 days of gestational age.

A previous study carried out on thalassemia major patients of Pakistani origin in the UK revealed that attitudes toward prenatal diagnosis and termination of pregnancy are influenced by a multitude of factors and not religion alone. ${ }^{18}$ Our study endeavored to explore other factors, along with religion, that could influence decisions regarding aborting an affected fetus. We were unable to relate factors like financial well-being, employment status, or region of residence to the decision regarding the outcome of pregnancy. This could be, in part, due to the limited sample size used in our study.
However, educational status of the mother had a significant impact on her decision; all the mothers who decided to continue with a pregnancy of an affected fetus had a very modest educational background. In contrast, the mothers who decided to abort the fetus were more educated than the mothers who chose to continue with the pregnancy. A study in Greece reinforces the general belief held by many in the biomedical world that education and economic reforms are critical for the success of public health campaigns like the thalassemia awareness program. They highlighted difficulties faced in translating scientific information to a semiliterate audience when even literate populations found it difficult to comprehend the complexities of genetic mutations. $^{23}$

\section{Study limitations}

The sample was a relatively small, non-probability convenience sample, taken from the TPFS records, which was not inclusive of all patients. Some districts could not be included in the study due to unavailability of records at the TPFS.

\section{Conclusion}

In Palestine, absence of a religious consensus on the acceptability of abortion is one of the foremost reasons behind reluctance to abort a fetus known to have $\beta$-thalassemia. With prevention being the only feasible way to control thalassemia, vague religious opinions will continue to compromise efforts to reduce the incidence of $\beta$-thalassemia. A focus on improving female education could empower women to take informed decisions that are best suited to their lifestyles.

Therefore, we recommend that thalassemia awareness programs should be implemented and their outreach increased. There is a need for people in Palestine to understand what the disease entails and the financial, social, and psychological implications of living with a child with thalassemia. Information on prenatal testing of thalassemia should be made more accessible to all, along with advocating early referrals for prenatal testing to give parents the option of a religiously accepted abortion.

\section{Acknowledgments}

We are extremely grateful to the participant mothers who contributed to this study to help us understand the factors associated with continuing emergence of $\beta$-thalassemia in Palestine, despite availability of prenatal testing. We would also like to acknowledge the immense support from the Thalassemia Patients' Friends Society in bringing this research project to fruition. 


\section{Author contributions}

Haleama Al-Sabbah, Abdallah Hamadna, Lamia Abu Ghazaleh, and Anwar Dudin designed the study, developed the questionnaire, and contributed to data collection while Sarah Khan assisted the abovementioned authors in data analysis and in writing the manuscript. Bashar Karmi from TPFS contributed to data collection. All authors contributed toward drafting and revising the paper and agree to be accountable for all aspects of the work.

\section{Disclosure}

The authors report no conflict of interest in this work.

\section{References}

1. Modell B, Darlison M. Global epidemiology of hemoglobin disorders and derived service indicators. Bull World Heal Organ. 2008;86(6): 480-487.

2. Hamosh A, Scott AF, Amberger J, Valle D, McKusick VA. Online Mendelian Inheritance In Man (OMIM). Hum Mutat. 2000;15(1):57-61.

3. Colah R, Gorakshar A, Nadkarni A. Global burden, distribution and prevention and beta-thalassemias and Hemoglobin E disorders. Expert Rev Hematol. 2010;3(1):103-117.

4. Smith Y. Thalassemia Prevalence. News Medical Life Sciences. http:// www.news-medical.net/health/Thalassemia-Prevalence.aspx. Published 2010. Accessed October 16, 2016.

5. Nathan DG. The treatment of Cooley's anemia. Haematologica. 1990; 75(5):57-65.

6. Davies SC, Roberts IA. Bone marrow transplant for sickle cell disease-an update. Arch Dis Child. 1996;75(1):3-6.

7. Ballantyne A, Newson A, Luna F, Ashcroft R. Prenatal diagnosis and abortion for congenital abnormalities: is it ethical to provide one without the other? Am J Bioeth. 2009;9(8):48-56.

8. Kuliev A, Rechitsky S, Verlinsky O, et al. Preimplantation diagnosis of thalassemias. J Assist Reprod Genet. 1998;15(5):219-225.

9. Karmi B. Annual Report of Thalassemia Patients' Friends Society 2009; 2009
10. Sirdah MM, Sievertsen J, Al-Yazji MS, et al. The spectrum of betathalassemia mutations in Gaza Strip, Palestine. Blood Cells Mol Dis. 2013;50(4):247-251.

11. Tarazi I, Al Najjar E, Lulu N, Sirdah M. Obligatory premarital tests for beta thalassemia in the Gaza Strip: evaluation and recommendations. Int J Lab Hematol. 2007;29(2):111-118.

12. World Health Organization. Amniocentesis and Chorionic Villus Sampling for Prenatal Diagnosis. Available from: https:/extranet.who.int/ rhl. Published 2006. Accessed October 15, 2016.

13. Akhlaghpoor S. Chorionic villus sampling for beta-thalassemia: the first report of experience in Iran. Prenat Diagn. 2006;26(12):1131-1136.

14. Ayesh SK, Al-Sharef WA, Nassar SM, Thawabteh NA, Abu-Libdeh BY. Prenatal diagnosis of Beta Thalassemia in the West Bank and Gaza. Saudi Med J. 2005;26(11):1771-1776.

15. Diwan F. The Palestinian public health law. F A T. 2009.

16. Agarwal S, Gupta A, Gupta UR, Sarwai S, Phadke S, Agarwal SS Prenatal diagnosis in beta-thalassemia: an Indian experience. Fetal Diagn Ther. 2003;18(5):328-332.

17. Dubey S. Chorionoc villous sampling for prenatal diagnosis in beta thalassemia. Indian Pediatr. 2005;42:499.

18. Ahmed S, Green JM, Hewison J. Attitudes towards prenatal diagnosis and termination of pregnancy for thalassemia in pregnant Pakistan women in the North of England. Prenat Diagn. 2006;26:248-257.

19. Alkuraya FS, Kilani RA. Attitude of Saudi families affected with haemoglobinopathies towards prenatal screening and abortion and the influence of religious ruling (Fatwa). Prenat Diagn. 2001;21(6): 448-451.

20. Ahmed S, Saleem M, Sultana N, et al. Prenatal diagnosis of betathalassemia in Pakistan: experience in a Muslim country. Prenat Diagn 2000;20:378-383.

21. Al-Matary A, Ali J. Controversies and considerations regarding the termination of pregnancy for foetal anomalies in Islam. BMC Med Ethics. 2014;15:10.

22. Palestinian Central Bureau of Statistics. Main statistical indicators. 2011; 28th October 2016. Available from: http://www.pcbs.gov.ps/ default.aspx.

23. Politis C, Richardson C, Yfantapoulos JG. Public knowledge of thalassemia in Greece and current concepts of the social status of the thalassemic patients. Soc Sci Med. 1991;32(1):59-64.
International Journal of Women's Health

\section{Publish your work in this journal}

The International Journal of Women's Health is an international, peerreviewed open-access journal publishing original research, reports, editorials, reviews and commentaries on all aspects of women's healthcare including gynecology, obstetrics, and breast cancer. The manuscript management system is completely online and includes

\section{Dovepress}

a very quick and fair peer-review system, which is all easy to use. Visit http://www.dovepress.com/testimonials.php to read real quotes from published authors. 